\title{
TUNGKU KRUSIBEL DENGAN ECONOMIZER UNTUK PRAKTIK PENGECORAN DI JURUSAN PENDIDIKAN TEKNIK MESIN FT UNY
}

\author{
Arianto Leman S. ${ }^{1)}$, Tiwan ${ }^{2)}$, Mujiyono ${ }^{3)}$ \\ 1,2,3 Program Studi Teknik Mesin Fakultas Teknik Universitas Negeri Yogyakarta \\ email: arianto_ls@uny.ac.id
}

\begin{abstract}
This research was aimed at developing economizer on aluminum crucible furnace to improve the furnace's performance. The research implements a Research and Development method. The economizer effects was determined from the performance test. The furnace were being tested with and without economizer at the same process condition. The developed furnace exhaust have the same diameter with the gas burner inlet. The exhaust was extended and curved to serve as economizer. Aluminum of $11.78 \mathrm{~kg}$ can be melted with the economizer effects in 60 minutes, and only required $2.6 \mathrm{~kg}$ of LPG, whereas without economizer it required 3.1 $\mathrm{kg}$ LPG in 80 minutes for the same amounts of Aluminum.
\end{abstract}

Keywords: crucible furnace, economizer, casting practice

\begin{abstract}
ABSTRAK
Penelitian ini bertujuan menambahkan economizer pada tungku pelebur aluminium untuk memperbaiki performa tungku. Metode Research and Development diterapkan untuk pengembangan tungku. Efek penggunaan economizer ditentukan dari uji kinerja. Tungku diuji coba tanpa dan dengan economizer pada kondisi proses yang sama. Saluran buang pada tungku berdiameter sama dengan saluran masuk. Saluran dibuat memanjang dan berbelok berfungsi sebagai economizer. Aluminium 11,78 kg dapat dicairkan memakai economizer dalam 60 menit dan membutuhkan 2,6 kg gas LPG, sedang tanpa economizer membutuhkan 3,1 kg gas LPG dan waktu 80 menit..
\end{abstract}

Kata kunci: alat bantu, pembelajaran kooperatif, deduktif

\section{PENDAHULUAN}

Saat ini proses pengecoran masih diterapkan dan menjadi pilihan utama dalam pembuatan komponen, karena dimungkinkan untuk membuat bentuk-bentuk rumit dengan konsistensi produk yang baik. Sebab itu, kompetensi mengecor logam merupakan salah satu kompetensi yang harus dikuasai lulusan sekolah menengah kejuruan (SMK) program keahlian teknik mesin. Hal ini telah tertuang dalam surat keputusan direktur jenderal pendidikan dasar dan menengah Kementerian Pendidikan dan Kebudayaan nomor: 4678/D/KEP/MK/2016 tanggal 2 September 2016 tentang spektrum keahlian pendidikan menengah kejuruan. Jurusan Pendidikan Teknik Mesin (JPTM) FT UNY adalah salah satu LPTK yang menghasilkan calon guru-guru program keahlian teknik mesin selayaknya memiliki sebuah tungku pelebur untuk mengembangkan kompetensi lulusan di bidang pengecoran logam.

Aluminium adalah logam ringan yang dipakai secara luas, bukan saja hanya untuk keperluan rumah tangga tetapi untuk keperluan bahan pesawat terbang, mobil, kapal laut dan konstruksi. Aluminium dan aluminium paduan tidak terlalu sulit dilebur karena suhu lelehnya rendah yaitu $660{ }^{\circ} \mathrm{C}$. Sebab itu, pengecoran aluminium banyak diaplikasikan di industri baik skala kecil, sedang maupun besar.

Peleburan aluminium skala kecil dan sedang biasanya dilakukan dengan tungku krusibel. Ciri khas tungku krusibel adalah digunakannya wadah untuk menempatkan logam yang akan di lebur. Wadah tersebut 
berbentuk krus yaitu menyerupai pot yang diameter atasnya lebih lebar sehingga disebut krusibel atau dikenal sebagai kowi. Tungku ini dibedakan menurut jenis bahan bakar yang digunakan yaitu, kokas atau arang, minyak dan gas. Sedang berdasar konstruksinya tungku dibedakan menjadi tungku dengan kowi tidak tetap, tungku dengan kowi tetap dan tungku tungkik.

Tungku berbahan bakar minyak lebih baik dari pada tungku berbahan kokas dan arang baik pembuatan, pengoperasian maupun efisiensi panasnya. Tungku ini tidak menghasilkan abu sisa pembakaran. Namun, minyak tanah dan solar saat ini agak sulit pengadaannya serta harganya relatif tinggi, sedang jika digunakan oli reidu, resiko pencemaran udara lebih tinggi. Lebih jauh, investasi pembelian burner relatif mahal tergantung pada ukuran dan kalori yang dihasilkan.

Gas LPG sebagai bahan bakar pada tungku krusibel telah banyak di aplikasikan. Gas LPG tidak menimbulkan abu, efisiensi panasnya baik dan ketersediaannya mencukupi. Supardi (2008) menelaah kinerja tungku pelebur aluminium kapasitas $6 \mathrm{~kg}$ berbahan bakar gas LPG dan oksigen. Dari hasil perhitungan diketahui tungku butuh gas LPG $0,0078 \mathrm{~kg} / \mathrm{menit}$ dan Oksigen 0,01198 $\mathrm{kg} / \mathrm{menit}$. Ella Sundari (2011: 17-26) telah mengembangkan rancang bangun tungku krusibel untuk melebur aluminium berbahan bakar gas. Tungku di buat dari drum bekas berukuran $\emptyset 590 \mathrm{~mm}$ x $490 \mathrm{~mm}$ dengan isolator dari batu bata. Pot di buat dari plat tebal $8 \mathrm{~mm}$ yang rol membentuk silinder berdiameter luar $220 \mathrm{~mm}$.

Arianto, dkk., (2014: 80-94) telah mengembangkan tungku krusibel berbahan bakar gas berkapasitas $15 \mathrm{~kg}$ aluminium cair. Tungku di buat dari drum bekas berukuran $\varnothing 600 \mathrm{~mm} \times 500 \mathrm{~mm}$. Isolator pada dinding samping memakai selimut keramik dan bata tahan api, sedang dibagian bawah memakai selimut keramik dan castable. Isolator pada tutup tungku hanya memakai castable, sehingga suhu bagian ini relatif tinggi saat peleburan. Tungku ini membutuhkan $2,7 \mathrm{~kg}$ gas elpiji selama 55 menit untuk mencairkan $8,6 \mathrm{~kg}$ aluminium.

Economizer adalah suatu perangkat tambahan pada sebuah alat atau mesin untuk meningkatkan efisiensi dan kinerja alat atau mesin. Economizer umumnya dipakai pada sistem boiler (M. Sjahid Akbar, dkk, 2009: 7281). Pemakaian economizer untuk furnace umumnya diterapkan pada furnace kapasitas besar. Economizer digunakan menangkap panas dengan perpindahan panas melalui pipa-pipa. Udara untuk pembakaran akan terpanaskan setelah melewati economizer sehingga efisiensi panas pembakaran dalam furnace meningkat.

Banyak usaha untuk meningkatkan efisiensi panas pada tungku krusibel. S. Stanworth, et. al. (1935), K.D. Hoke (1941), dan L.J. Lazardis (1972) memperkenalkan inovasi-inovasi untuk memanfaatkan panas yang terbuang bersama sisa pembakaran gas yaitu dengan menempatkan saluran buang berdekatan atau bersinggungan dengan saluran masuk sehingga panas dari saluran buang akan ditransfer ke saluran masuk secara konduksi. Bagaimanapun, inovasi-inovasi yang telah dilakukan ini secara konstruksi terlalu rumit sehingga kurang sesuai jika diaplikasikan pada tungku krusibel untuk kebutuhan praktik di laboratorium.

Modifikasi terhadap saluran buang sisa pembakaran gas dilakukan untuk memperbaiki performa tungku krusibel kapasitas kecil. Saluran buang difungsikan sekaligus sebagai economizer. Penambahan economizer akan ditelaah pada penelitian ini. Economizer yang dikembangkan harus sederhana dan mudah dibuat agar sesuai diterapkan pada tungku krusibel sederhana. Dengan demikian sesuai diterapkan di industri kecil maupun tungku krusibel untuk mendukung praktik di laboratorium.

\section{METODE}

Tungku krusibel untuk meleburkan aluminium dikembangkan dengan tahapan: (1) 
analisis kebutuhan, (2) pengembangan desain; (3) persiapan alat dan bahan, (4) pengembangan tungku, (5) uji coba pertama, (6) evaluasi dan revisi, (7) uji coba kedua, (8) evaluasi dan revisi, (9) uji kinerja.

Uji kinerja dilaksanakan setelah seluruh komponen tungku krusibel tersedia, terpasang dan berfungsi dengan baik. Uji kinerja dilaksanakan dengan langkah-langkah dan batasan-batasan tertentu. Pertama, pengujian dilakukan pada tungku krusibel tanpa economizer. Tabung LPG beserta isinya ditimbang sebelum dan setelah pengujian untuk mengetahui kebutuhan gas LPG. Peningkatan suhu dinding pada tungku di catat setiap 10 menit sampai aluminium mencair. Langkah ini diulangi pada tungku krusibel dengan economizer. Seluruh pamameter operasi tungku krusibel yaitu bukaan katup udara blower, bukaan regulator blower dan bukaan regulator tabung gas LPG diatur sedemikian sehingga sama untuk pengujian tungku krusibel dengan economizer dan tanpa economizer. Walaupun pengujian dilakukan pada hari yang berbeda, namun kondisi suhu luar sekitar tungku saat pengujian diasumsikan sama karena pengujian dilakukan pada waktu dan tempat yang sama.

Seluruh data pengujian dicatat, di ambil reratnya kemudian dibandingkan. Hasil data tersebut kemudian dianalisis secara deskriptif dan kemudian diambil kesimpulan

\section{HASIL DAN PEMBAHASAN}

Tungku pelebur aluminium dibuat dari drum bekas berdiamater $\varnothing 600 \mathrm{~mm}$ dan dipotong sehingga tingginya menjadi $500 \mathrm{~mm}$. Isolator tungku adalah kombinasi selimut keramik dan castable berpenguat baja baja $\varnothing 6$ $\mathrm{mm}$ (Gambar 1). Dinding bagian dalam tungku terdiri atas tiga buah dinding castable. Ketiganya disusun secara bertingkat didalam tungku dan direkatkan dengan air setting mortar. Pada drum dibuat dua lubang, satu untuk input panas dari burner gas dan lainnya untuk output sisa pembakaran gas. Sistem tungku terdiri atas dua buah rangka, yaitu rangka penopang tungku dan rangka untuk sistem burner gas. Tutup dan tutup atas tungku dibuat dari baja setebal $2 \mathrm{~mm}$ dengan isolator kombinasi selimut keramik (Gambar 2) dan castable berpenguat baja $\emptyset 6 \mathrm{~mm}$ yang di las ke dinding tutup. Setelah semua komponen tungku selesai dibuat, kemudian dirakit.

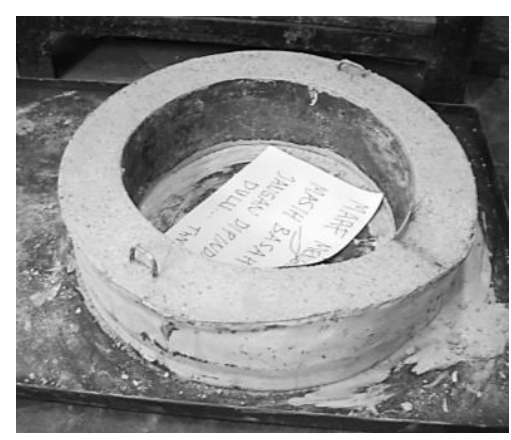

Gambar 1. Dinding dari castable

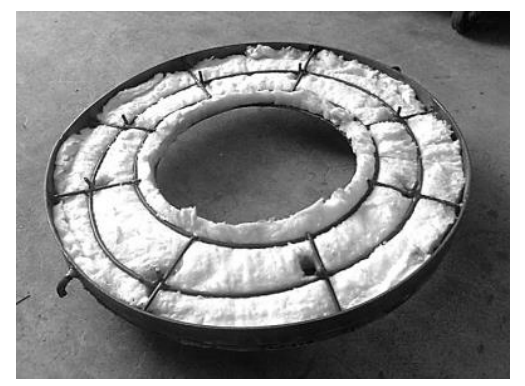

Gambar 2. Selimut keramik pada tutup

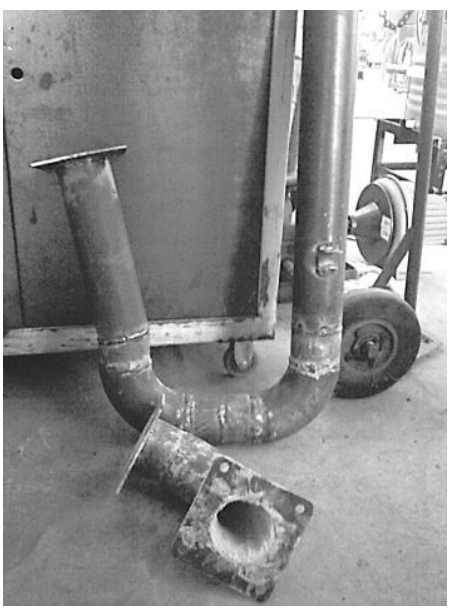

Gambar 3. Saluran buang yang dipanjangkan

Saluran buang sisa pembakaran gas dibuat memanjang dan berbelok. Saluran ini didesain sekaligus berfungsi sebagai economizer (Gambar 3 dan 4). Cara kerja economizer ini tidak seperti economizer pada 
boiler. Saluran buang yang dibuat memanjang dan berbelok ini dimaksudkan agar panas dari dalam tungku tidak langsung terbuang keluar, namun agak tertahan di dalam tungku. Dengan demikian suhu di dalam tungku akan lebih tinggi sehingga diharapkan waktu untuk melebur aluminiun lebih singkat.

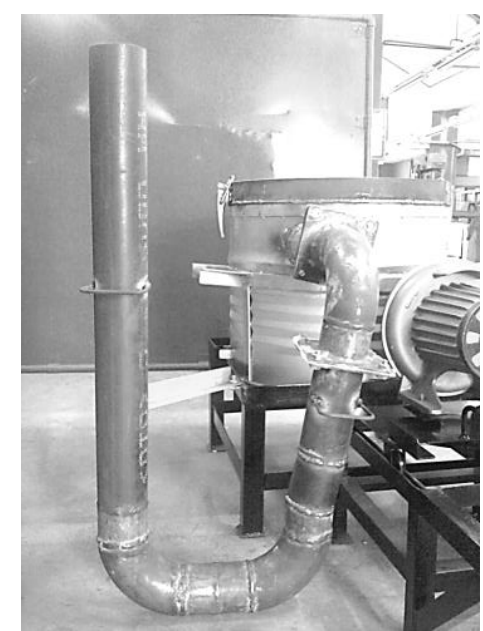

Gambar 4. Saluran buang pada tungku sebagai economizer

Uji coba pertama dilakukan untuk mengetahui kekurangan dan kelemahan tungku. Pengujian dilakukan tanpa melebur aluminium. Pada pengoperasian gas burner jumlah udara masuk harus sesuai agar pembakaran bisa sempurna. Awalnya, katup udara gas burner dibuka cukup besar agar pasokan oksigen saat penyalaan cukup sehingga gas dapat terbakar sempurna. Setelah blower pada gas burner di hidupkan, katup pengatur udara dikecilkan agar jumlah oksigen tidak terlalu kaya. Blower gas burner akan menghisap udara sehingga katup perlu dikecilkan agar oksigen tidak berlebihan.

Namun, pada uji coba pertama ini gas burner selalu mati saat katup pengatur udara di kecilkan. Saat jumlah pasokan oksigen ditambah dengan tidak menutup katup terlalu kecil saat blower dihidupkan ternyata menyebabkan timbulnya asap hitam yang berlebihan akibat pembakaran yang terlalu kaya oksigen yang berarti pula menunjukkan pembakaran tidak sempurna. Lebih jauh, hal ini juga menyisakan jelaga hitam sisa pembakaran pada seluruh dinding dalam tungku. Kondisi ini menyebabkan konsumsi gas LPG boros dan suhu target tidak dapat tercapai.

Hasil analisis menunjukkan bahwa penyebab hal ini adalah terjadinya tabrakan antara semburan gas hasil pembakaran dari blower dengan gas sisa hasil pembakaran yang berputar di dalam tungku. Semburan gas hasil pembakaran akan terdorong masuk menabrak dinding tungku dan berputar mengelilingi dinding tungku sehingga berbenturan dengan semburan dari gas burner. Semburan gas hasil pembakaran yang banyak mengandung karbon dioksida membentur gas yang disemburkan gas burner bahkan ada sebagian yang berbalik keluar melalui saluran masuk. Hal ini menyebabkan oksigen yang di pasok dari gas burner harus ditambah dengan membuka katup pengatur oksigen lebih lebar. Hal ini dapat menyebabkan kerusakan pada gas burner karena semburan balik ini membuat gas burner menjadi panas yang akhirnya dapat merusak gas burner.

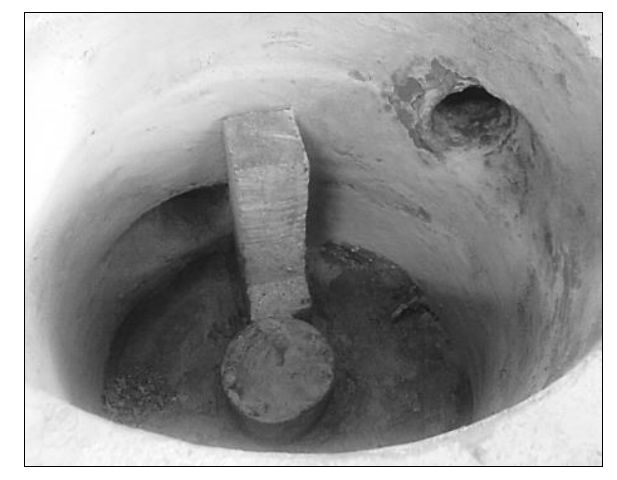

Gambar 5. Penghalang dari batu tahan api

Revisi yang dilakukan untuk mengatasi hal ini, adalah menambahkan penghalang dari batu tahan api (Gambar 5). Penghalang akan mengarahkan semburan gas hasil pembakaran dari saluran input ke atas dan keluar melalui saluran buang. Dengan revisi ini, pasokan oksigen dapat diatur sesuai kebutuhan sehingga konsumsi gas LPG lebih hemat dan tidak menyisakan jelaga hitam pada dinding tungku.

Pada uji coba kedua tungku dipakai untuk melebur aluminium. Tungku dapat melubur aluminium sekitar $8 \mathrm{~kg}$ aluminium dalam waktu sekitar 50 menit. Hasil ini tentu 
saja tidak sesuai dengan target yang diharapkan. Pada saat uji coba tersebut, terdapat beberapa komponen yang belum terpasang yaitu: regulator, pengukur tekanan (mBar) dan pengukur tekanan (Bar). Komponen-komponen ini berfungsi untuk mengatur dan mengontrol aliran gas dari tabung gas LPG ke gas burner. Dengan demikian keberadaan komponenkomponen tersebut sangat penting untuk menghasilkan proses pembakaran yang efisien. Akibatnya, saat uji coba kedua ini, kinerja tungku masih belum optimal.

Regulator yang dipasang pada tabung LPG sudah dilengkapi pengukur tekanan gas. Namun, fungsi komponen ini lebih ditujukan pada kontrol ketersediaan gas di dalam tabung. Pengukur tekanan (Bar), pengatur tekanan atau regulator (mBar) dan pengukur tekanan (mBar) diperlukan untuk mengatur aliran gas menuju burner agar semburan api dapat dijaga konstan. Komponen-komponen tersebut dipasang sebagai sebuah kesatuan sistem gas burner pada rangka penyangga burner (Gambar 6). Tiap komponen pada sistem ini dihubungkan oleh sebuah selang untuk mengalirkan gas dari tabung gas LPG menuju gas burner. Aliran gas dapat dikontrol sesuai kebutuhan untuk memperoleh pembakaran gas yang sempurna dan efisiensi pemanasan yang lebih baik.

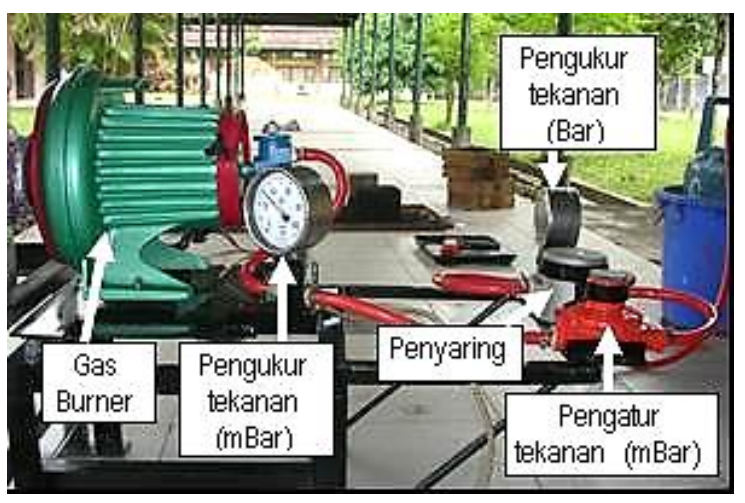

Gambar 6. Rangkaian sistem gas burner

Uji kinerja ditujukan untuk mengetahui kinerja tungku dengan economizer. Langkah yang ditempuh adalah menguji tungku untuk melebur aluminium dengan dan tanpa econimizer. Pengujian dilakukan pada kondisi dan variabel yang di buat konstan. Variabel tersebut adalah bukaan regulator tabung gas LPG, pengukur tekanan (Bar), pengatur tekanan (mBar), pengukur tekanan (mBar), bukaan aliran udara dan kran gas pada burner serta bobot aluminium yang akan dilebur. Uji kinerja tungku tanpa dan dengan economizer dilakukan pada hari yang berbeda karena tidak mungkin dilakukan pada satu hari yang sama. Namun demikian, pengujian dilakukan pada jam dan tempat yang sama sehingga diasumsikan pengaruh suhu lingkungan sekitar tungku dapat diabaikan.

Bobot aluminium yang dilebur pada uji coba adalah $11,78 \mathrm{~kg}$. Tekanan pada pengukur tekanan Bar adalah 1,2 Bar, pada pengukur tekanan mBar adalah $34 \mathrm{mBar}$, sedang bukaan keran pada gas burner pada skala 3. Tungku tanpa economizer membutuhkan $3,122 \mathrm{~kg}$ gas LPG dan 80 menit untuk mencairkan $11,78 \mathrm{~kg}$ aluminium. Pada pengujian tungku dengan economizer hanya butuh 2,6 kg gas LPG dan 60 menit untuk mencairkan $11,78 \mathrm{~kg}$ alumnium. Hasil uji kinerja menunjukkan bahwa saluran buang yang di fungsikn sebagai economizer dapat memperbaiki performa tungku krusibel dalam melebur aluminium (Gambar 7).

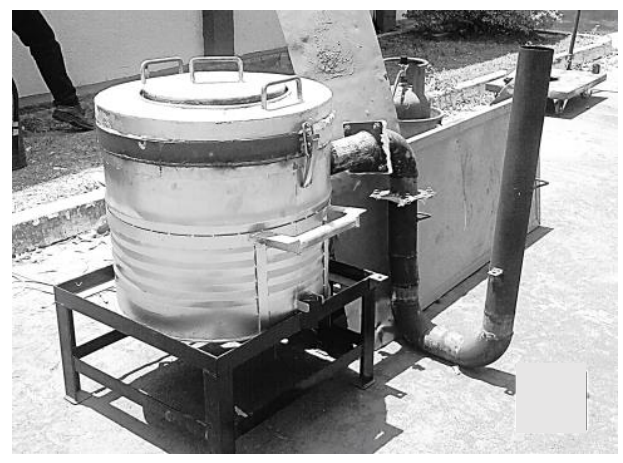

Gambar 7. Pengujian tungku krusibel dengan ecnomizer

Hasil uji kinerja menunjukkan bahwa penggunaan economizer mampu memperbaiki efisiensi tungku dalam melebur aluminium. Hal ini berarti bahwa tungku layak digunakan sebagai alat bantu dalam mendukung praktikum pengecoran di JPTM FT UNY dilihat dari sisi 
waktu, kebutuhan bahan bakar gas, maupun kapasitas aluminium yang dilebur.

Tabel 1 menunjukkan bahwa suhu saluran buang tungku saat diuji dengan economizer tampak lebih tinggi dibanding saat tungku diuji tanpa economizer. Hal ini menunjukkan bahwa suhu didalam tungku saat beroperasi dengan economizer juga lebih tinggi. Kondisi ini terjadi karena panas hasil pembakaran gas burner tidak langsung terbuang keluar, namun sedikit terhambat karena gas buangan dibelokkan terlebh dahulu oleh economizer. Keadaan ini akan mempercepat cairnya aluminium di dalam kowi. Namun, saluruan buang yang dibuat mempanjang dan berbelok tersebut tidak menyebabkan tekanan di dalam tungku meningkat. Diameter saluran gas buang yang sama dengan diameter saluran masuk tidak menyebabkan naiknya tekanan di dalam tungku. Ini berarti tungku dengan economizer lebih efisien baik dari waktu peleburan maupun pemakaian gas LPG. Tungku dengan economizer lebih efisien di banding tungku yang sebelumnya telah dikembangkan oleh Arianto, dkk (2014: 80-94).

Tabel 1. Pengukuran suhu bagiabn-bagian tungku saat aluminium mulai mencair

\begin{tabular}{|c|c|c|c|c|}
\hline \multirow{2}{*}{ BAGIAN } & \multirow{2}{*}{ GAMBAR } & \multirow{2}{*}{$\begin{array}{c}\text { Titik } \\
\text { Pengukuran }\end{array}$} & \multicolumn{2}{|c|}{ Suhu rata-rata $\left({ }^{\circ} \mathrm{C}\right)$} \\
\hline & & & Tanpa economizer & Dengan economizer \\
\hline 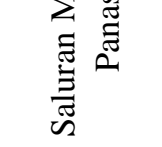 & & 1 & 116,23 & 54,60 \\
\hline$\stackrel{\Xi^{2}}{\vec{z}}$ & & 1 & 62,37 & 47,53 \\
\hline$\stackrel{0}{0}$ & & 2 & 88,13 & 63,80 \\
\hline & & 1 & 58,03 & 51,93 \\
\hline 2 & & 2 & 61,80 & 57,87 \\
\hline & & 1 & 234,17 & 224,80 \\
\hline $\begin{array}{l}\text { E } \\
\text { a }\end{array}$ & & 2 & 205,80 & 158,83 \\
\hline & & 3 & 173,43 & 102,83 \\
\hline & & $1 \mathrm{~A}$ & 141,03 & 278,03 \\
\hline$\stackrel{500}{\Xi}$ & & 1B & 56,00 & 77,07 \\
\hline 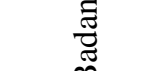 & & $2 \mathrm{~A}$ & 69,00 & 55,70 \\
\hline & & $2 \mathrm{~B}$ & 72,20 & 48,77 \\
\hline
\end{tabular}




\begin{tabular}{|c|c|c|c|c|}
\hline \multirow{2}{*}{ BAGIAN } & \multirow{2}{*}{ GAMBAR } & \multirow{2}{*}{$\begin{array}{c}\text { Titik } \\
\text { Pengukuran }\end{array}$} & \multicolumn{2}{|c|}{ Suhu rata-rata $\left({ }^{\circ} \mathrm{C}\right)$} \\
\hline & & & Tanpa economizer & Dengan economizer \\
\hline $\begin{array}{l}\frac{\pi}{\infty} \\
\infty \\
\infty \\
\equiv \\
\equiv\end{array}$ & & 1 & 365,37 & 434,33 \\
\hline 焉 & & 2 & 280,83 & 349,30 \\
\hline
\end{tabular}

Bagaimanapun, uji kinerja ini hanya untuk mengetahui keuntungan penggunaan economizer secara umum dalam meningkatkan efisiensi panas tungku. Penelaahan lebih lanjut masih diperlukan untuk menentukan kondisi pengaturan pengoperasian tungku agar diperoleh proses peleburan yang optimal. Lebih jauh, peningkatan efisiensi tungku dengan economizer juga belum dapat dikuantifikasi secara rinci karena optimasi kinerja tungku secara spesifik belum diketahui.

\section{SIMPULAN}

Hasil pengembangan tungku pelebur aluminium yang telah dilakukan adalah: (1) saluran buang pada tungku berdiameter sama dengan saluran masuk. Saluran dibuat memanjang dan berbelok berfungsi sebagai economizer yang mampu meningkatkan suhu dalam tungku dan meningkatkan efisiensi proses peleburan, (2) aluminium $11,78 \mathrm{~kg}$ dicairkan oleh tungku dengan economizer dalam 60 menit dan membutuhkan 2,6 kg gas LPG, sedang tungku tanpa economizer membutuhkan 3,1 kg gas LPG dalam 80 menit.

Optimasi pengoperasian tungku ini masih perlu ditelaah melalui sebuah studi tersendiri untuk mengembangkan Prosedur Operasional Standar tungku. Optimasi proses pengoperasian tungku berkaitan dengan pengaturan aliran gas LPG untuk memperoleh pembakaran gas burner yang efisien. Optimasi ini meliputi pengaturan regulator tabung gas yang dikontrol melalui pengukur tekanan dalam satuan Bar, pengaturan regulator gas setelah penyaring yang dikontrol melalui pengukur tekanan dalam satuan mBar, pengaturan keran gas burner dan pengaturan bukaan asupan udara atau oksigen pada gas burner.

\section{UCAPAN TERIMAKASIH}

Penulis mengucapkan terimakasih kepada Ketua Jurusan Pendidikan Teknik Mesin FT UNY yang teleh memberi ijin untuk menggunakan fasilitas-fasilitas yang ada di Jurusan Pendidikan Teknik Mesin FT UNY

\section{DAFTAR RUJUKAN}

Arianto L.S. dan Tiwan, (2014), Pengembangan Tungku Peleburan Aluminium untuk Mengembangkan Kompetensi Pengecoran Di SMK Program Studi Keahlian Teknik Mesin, INOTEK, 18 (1), 80-94.

Ella Sundari, (2011). Rancang Bangun Dapur Peleburan Alumunium Bahan Bakar Gas, Jurnal Austenit, 3 (1), 17-26.

Hoke, KD., (1941). Crucible Furnace, United States Patent, Patent No.: 2.253.707.

Lazardis, LJ., (1972). Crucible Furnace, United States Patent, Patent No.: 3.667.745.

M. Sjahid Akbar, Fredi Suryadi, Dedy Dwi Prastyo, (2009), Kinerja Economizer Pada Boiler, Jurnal Teknik Industri, 11 (1), 72-81.

Supardi, (2008). Kinerja Tungku Peleburan Aluminium Kapasitas $6 \mathrm{~kg}$ Dengan Bahan Bakar Gas LPG dan Oksigen, diakses 3 April 2013, 10.30 WIB dari http://karyailmiah.tarumanagara.ac.id/ind ex.php/S1TM/article/view/771,

Stanworth, S., et. al. (1935). Gas Fired Furnace, United States Patent, Patent No.: 1.996.660. 